\title{
ARQUEOLOGIA DA PAISAGEM: A INFLUÊNCIA DOS FATORES CAUSADORES DE NAUFRÁGIOS DO SÉCULO XVI NO MAR ADJACENTE AO PORTO DO RECIFE, PE, BRASIL ARCHAEOLOGY OF THE LANDSCAPE: THE INFLUENCE OF SHIPWRECKS CAUSING FACTORS IN XVI CENTURY IN THE ADJACENT SEA TO THE PORT OF RECIFE, PE, BRAZIL
}

\section{Carlos Rios}

cccrios@hotmail.com

Depto. Arqueologia, PhD, UFPE.

Valdeci dos Santos Júnior

valdecisantosjr@hotmail.com

Depto. História, PhD, UERN.

Daline Lima de Oliveira

daline.bs@hotmail.com

Graduanda em Arqueologia - UNIVASF.

\section{RESUMO}

O trabalho versa sobre a interpretação dos naufrágios ocorridos no século XVI, no mar adjacente ao porto do Recife, Estado de Pernambuco, Brasil, sob a ótica da análise espacial da paisagem, com o objetivo de identificar quais foram os fatores causadores de naufrágios que contribuíram para esses soçobros. Os procedimentos metodológicos foram o levantamento do número de naufrágios, plotagem em carta náutica dos locais de afundamento, análise cartográfica do relevo marinho atual, estudo de mapas históricos sobre a geomorfologia pretérita, dimensões aproximadas dos navios com seus respectivos calados, regime de ventos e correntes marítimas. Os resultados permitiram levantar inferências sobre as causas desses naufrágios, derivados do desconhecimento dos navegantes de uma análise espacial mais consistente da paisagem natural, especificamente voltados aos fatores hidrometeorológicos e cartográficos.

Palavras-chave: Arqueologia subaquática. Análise da paisagem. Fatores hidrometeorológicos.

\section{ABSTRACT}

The work deals on the interpretation of the shipwrecks that occurred in the sixteenth century, the adjacent sea to the port of Recife, Pernambuco State, Brazil, from the perspective of spatial analysis of the landscape, in order to identify what were the factors causing shipwrecks that contributed for these sinking. The methodological procedures 
were lifting the number of shipwrecks, plotting nautical chart of ditching sites, cartographic analysis of the current marine relief, study of historical maps on the preterit geomorphology, approximate size of the vessels with their quiet, the winds and currents sea. The results raise inferences about the causes of such wrecks, derived from the lack of sailors in a more consistent spatial analysis of the natural landscape, specifically geared to hydrometeorological and cartographic factors.

Keywords: Underwater archeology. Landscape analysis.Hydrometeorological factors. paisagem. Fatores.

\section{INTRODUÇÃO}

Em 09 de março de 1535 Duarte Coelho, donatário da Capitania de Pernambuco, chega ao Brasil e fixa residência em Igarassú. No entanto, devido a problemas de segurança e animosidade com os nativos daquela área, decidiu pelo deslocamento definitivo para o povoado de Olinda. Passou a morar com familiares no Alto da Sé, local estratégico, com visão privilegiada do mar a sua frente até a linha do horizonte e do litoral sul até o Cabo de Santo Agostinho (MELLO e ALBUQUERQUE, 1997; PERREIRA DA COSTA, 1983).

Inicialmente, as soluções provisórias para desembarque em Olinda foi a construção de um trapiche, entre a praia adjacente onde está, na atualidade, a igreja dos Milagres e o bairro do Umuarama, bem como um varadouro no rio Beberibe, cujo local passou a ser conhecido como "Varadouro das Galeotas". Aquele era o lugar onde as embarcações de pequeno porte varavam terra com mercadorias diversas vindas da Europa nos grandes navios (PERREIRA DA COSTA, 1983).

Posteriormente, optou-se pelo porto natural, o de "Pernambuco Novo", como assim era chamado o atual porto do Recife. Ele teve a sua escolha baseada na proteção natural formada pelo cordão de recifes de origem Holocênica, que protege o istmo de Olinda do embate diuturno das ondas, além de boa parte da profundidade local ser condizente com o calado das embarcações e possuir ampla área livre para manobra.

O porto está localizado nas coordenadas geográficas $08^{\circ} 03^{\prime} 22^{\prime \prime} \mathrm{S}$ e $034^{\circ} 51^{\prime}$ '57' W (Datum SAD 69), na área adjacente ao Povo, Recife dos Navios, Ribeira das Naus, dentre outros tantos nomes dados para aquele povoado cosmopolita, que crescia a 3 léguas distantes da Nova Lusitânia (Olinda) (GUERRA, 1954). O cordão de recifes ou arrecifes - defronte ao porto - era interrompido por uma barreta, uma diante do atual forte das Cinco Pontas (barreta dos Afogados, fechada em 1840), próxima ao atual Iate Clube de Recife e duas barras vizinhas ao forte da Lage, sofrendo outros processos de descontinuidade dos arrecifes defronte as ruínas do forte de Santo Antônio do Buraco.

Externamente, o mar adjacente ao porto de Pernambuco Novo é o mesmo da atualidade, é chamado de "Lamarão" ou "Lameirão". O termo "Lamarão", segundo Pereira da Costa (1983), aparece pela primeira vez em 1579, quando uma flotilha, comandada por Frutuoso Barbosa, Capitão-mor da conquista da Paraíba, surgiu em Pernambuco e fundeou no referido local. O "Lamarão" compreende a área retangular de $12 \mathrm{~km}$ de comprimento por $2 \mathrm{~km}$ de largura da plataforma continental interna, defronte ao porto do Recife, com profundidade variando entre $10 \mathrm{~m}$ e $25 \mathrm{~m}$, cujo fundo é arenoso, com pequenos bolsões de lama, alguns afloramentos rochosos e arrecifes submersos (RIOS, 2007).

No espaço entre os arrecifes e o estirâncio ${ }^{1}$ do istmo de Olinda, cuja largura variava de 40 a $100 \mathrm{~m}$, "Pernambuco Novo" estava dividido por duas coroas de areia que apareciam, parcialmente, na baixa-mar formando uma passagem em 
S, ficando ao norte, mais próximo a Olinda, "o Poço", com profundidade de até 24 pés e uma área de manobra de $400 \mathrm{~m}$ de largura e, ao sul, o "Mosqueiro", com profundidade de 16 pés e espaço para fainas marinheiras de $150 \mathrm{~m}$. Na altura do Mosqueiro, porção mais distal do istmo, ficava umas poucas tabernas, algumas moradias e armazéns para estoque de açúcar, madeiras e couros. A população local era bastante diversificada, no que concerne a nacionalidade, mas tinham algo em comum: eram pescadores ou trabalhavam em alguma profissão voltada para os misteres do mar, como calafates, tanoeiros, estivadores, estrinqueiros, mestres carpinteiros, fundidores e marinheiros (RIOS, 2007).

O porto de "Pernambuco Novo" tornou-se referência para os navegantes que vinham da Europa ou da Ásia, isto porque, além de fornecer pessoal qualificado para tripulação de todos os tipos de navio, existia aguada de boa qualidade coletada em tonéis e transportada por escravos em canoas monóxilas no rio Beberibe, nas proximidades do engenho Velho, bem como lenha, sobressalentes para os navios e víveres (LINS JUNIOR, 2015).

Em face ao relevo acidentado com inúmeros recifes submersos, coroas, baixios, além de correntes e ventos fortes, nos meses de inverno, a boca da barra - tanto para saída quanto para entrada - não era tarefa fácil de ser cumprida. Essa paisagem irregular contribuiu para o soçobro de navios de diversos tipos e nacionalidades.

Não se tem registro de como era realizado o balizamento de entrada no porto de "Pernambuco Novo" nos dois primeiros quartéis do século XVI. A primeira "carta náutica" com descrição batimétrica dos canais de acesso é de 1585, mas inexistem balizas chantadas ou marcos fixos (colunas) que possam ser interpretados com essa finalidade como existia para barra da Ilha de Itamaracá (ALBERNAZ, 1968).

A primeira baliza que se tem conhecimento para o porto vem a ser a "Cruz do Patrão", mas data de 1759 e fazia alinhamento com a torre da igreja de Santo Amaro das Salinas que é de 1680, cujo espaço temporal foge ao período estudado. Neste contexto, o porto de "Pernambuco Novo" (Recife), do mar para terra, se apresentava com uma área de fundeio (lamarão externo), com dois canais de acesso (Norte ou de Olinda e do Sul), separados pelo banco Inglês. Tal banco é um cordão de recifes medindo $1.847 \mathrm{~m}$ de comprimento por $22 \mathrm{~m}$ de largura, portanto, com duas possibilidades de entrada da barra principal: o canal Norte em sua parte mais rasa com 16 pés de calado e o Sul em sua parte de menor profundidade com 24 pés (RIOS et al. 2013).

A entrada da barra principal, levando-se em consideração a boca de um galeão de grande porte $(20 \mathrm{~m})$, tinha cerca de $40 \mathrm{~m}$, calando 24 pés, até o leito marinho. Permitia, desse modo, a passagem para embarcações de até 21 pés de calado, tendo como proteção os fortes da Lage e de São Jorge na entrada da barra, a boreste o "baixio da Tartaruga", que era um perigo a navegação, visível apenas na maré baixa, seguido de um cordão irregular de recifes, onde está o "baixio do Galeão", que se prolonga por toda a costa pernambucana.

Uma vez vencido esses obstáculos naturais, o porto era dividido em duas partes: Poço (lamarão interno), com profundidade média de 24 pés que, na atualidade, corresponde aos cais de 01 a 06; Mosqueiro (lamarão interno), com profundidade de 16 pés que vai do cais 07 ao 14 . As duas partes eram divididas por dois bancos de areia que formam uma passagem em S(RIOS et al. 2013).

Havia também a "Barreta dos Afogados" que ficava na altura do atual Iate Clube do Recife, com largura e profundidade desconhecidas, a qual, possivelmente, permitia a passagem de barcos com pouco calado, tendo como proteção o forte das Cinco Pontas construído em 1630 (ALBUQUERQUE, 
1999). Os navios de maior calado (acima de 25 pés) ficavam fundeados nas "Laminhas" que era a área compreendida entre o banco Inglês e os Baixios da Tartaruga e do Galeão, ficando botes, escaleres, canoas, jangadas e barcaças responsáveis pelo transbordo de cargas e pessoas para terra (RIOS et al. 2013).

Portanto, para que as embarcações maiores atracassem no Porto de "Pernambuco Novo" com segurança, seria necessário aos navegantes, uma compreensão dos mapas cartográficos locais, assim como de uma análise atenta da paisagem natural e dos fatores físicos do entorno que pudessem eventualmente colocar em risco as operações náuticas. Entretanto, mesmo já existindo um conhecimento cartográfico daquela área pelos portugueses no século XVI, alguns naufrágios aconteceram. Nesse contexto, o trabalho tem como principal objetivo analisar os fatores causadores de naufrágios, através da ótica da arqueologia da paisagem do Porto do Recife, para entender as causas dos soçobros que ocorreram no século XVI.

\section{PAISAGEM E O LUGAR NO PORTO DO RECIFE}

Durante milhares de anos, a paisagem ambiental não era percebida pelos viajantes como fazendo parte das relações humanas, mas apenas como um espaço natural no qual as embarcações navegavam.

Entretanto, essa paisagem compreende um intervalo espacial como um meio sempre envolvido na ação, não podendo dela ser separado e esse espaço é socialmente produzido. Não haveria um espaço, mas espaços, que combinariam os meios cognitivo, físico e emocional e, por envolverem esta dimensão cognitiva, os espaços "não podem ser entendidos fora das vivências simbolicamente constituídas dos atores sociais" ou, por outra, que um espaço pode ser construído e reproduzido, que "ele não possui essência substancial própria, somente existindo a partir das relações entre pessoas e lugares" (TILLEY, 1994). Esse espaço, a partir de uma construção ideológica, passa a ter três dimensões: o espaço enquanto entorno físico ou matriz do meio ambiental da ação humana, o espaço enquanto entorno social onde se produzem as relações entre indivíduos e grupos e o espaço enquanto meio simbólico (BOADO, 1999).

Esse espaço, socialmente construído, tem uma significância própria que constitui o lugar, com suas especificidades, entre as quais entram em cena os próprios fatores causadores de naufrágios. Dessa forma, os lugares não são apenas uma superfície onde ocorrem ações, ou pontos demarcados no espaço, eles são a conjunção de uma série de elementos, tanto internos quanto externos ao sujeito. Ao mesmo tempo, caracterizam-se como um local físico e um centro de significados, sendo esse espaço transformado em lugar quando é envolvido pela ação humana. Assim, um espaço se transforma em lugar a partir do momento em que é envolvido, direta ou indiretamente, pelas ações humanas:

"O produto da interação do homem com o meio é o que faz o lugar porque, na sua ausência, o lugar é sítio de características físicas, às quais o homem não criou relação emotiva e simbólica. Assim, o simbolismo do lugar representa não só as características físicas do mesmo como também uma transformação no interior do homem que permite a atribuição de um significado mítico, transformando-o num lugar significante (FERRO, 2004, p. 15).”

A significância do lugar (porto) está inserida dentro da paisagem arqueológica e do meio físico que o cerca (relevo submarino, correntes e ventos) 
e dela não pode ser dissociada. Essa utilização do meio físico, que é socialmente apropriada pelo homem para a produção da cultura material, se dá através de comportamentos humanos de intervenção direta no meio ambiente, modelando e dando formas, segundo determinados propósitos e normas adotadas. Será necessário, portanto, entender esses comportamentos que originaram determinadas escolhas nas construções das paisagens que foram, de certa forma, alteradas por essas intervenções culturais.

As pessoas, geralmente, percebem, classificam e moldam a paisagem circundante a partir de processos simbólicos que podem estar vinculados às tradições culturais do grupo, ou seja, as preocupações que guiam as abordagens processuais e refletem a inserção de uma quarta partícula de interrogação na compreensão do contexto arqueológico, além de "que", "quando" e "onde", será necessário entender o "como" foram produzidos os vestígios arqueológicos e a distribuição diferencial dos naufrágios no espaço.

Geralmente, se percebe, classifica e molda a paisagem circundante a partir de processos simbólicos que podem estar vinculados às tradições culturais do grupo. Para tanto, será necessário entender, além do "por que", "quando" e "onde", o modus operandi do fato e como foram produzidos os vestígios arqueológicos e a distribuição diferencial dos sítios arqueológicos subaquáticos ${ }^{2}$ nesse espaço.

\section{METODOLOGIA}

Para responder ao questionamento sobre quais fatores foram os causadores de naufrágios no porto do Recife, no século XVI, os procedimentos metodológicos incluíram: pesquisas bibliográficas de autores nacionais e estrangeiros; correlações iconográficas de imagens de mapas cartográficos atuais e antigos de pontos conhecidos, tais como banco Inglês, baixio do Galeão, cabeço da Tartaruga e forte da Lage, bem como o estudo comparado dos calados e profundidades locais, além de plotagem, em carta náutica, de naufrágios do período trabalhado e confecção de uma tabela de naufrágios.

\section{OS FATORES HIDROMETEOROLÓGICOSE CARTOGRÁFICOS DO PORTO DO RECIFE}

Dos fatores hidrometeorológicos, o regime de ventos é o principal agente na formação das correntes costeiras. Deste modo, foram estudadas as cartas sinóticas ${ }^{3}$ do litoral pernambucano, que apontam as direções NE/SE como sendo os principais sentidos dos ventos para o litoral de Pernambuco, criando monções distintas.

\section{O REGIME DE VENTOS}

No que concerne ao regime de ventos oceânicos vindos do Hemisfério Sul, predominam os de SE, também chamados de alísios de SE. Sua ação é sentida durante todo o ano na região estudada. No entanto, em decorrência do movimento de rotação da Terra, atinge a costa em direções variáveis, mudando no decorrer do ano. A ação de tais ventos, no trecho compreendido entre o Cabo Calcanhar - RN e o Rio São Francisco - SE, é SE, oscilando até E. Essa ação cria as duas monções supracitadas: a Nordeste e a Sudeste (GUEDES, 1975). 
No porto do Recife, o regime de ventos para os meses de inverno é de SE e, com força variando entre $5 \mathrm{~m} / \mathrm{s} \mathrm{e} 6 \mathrm{~m} / \mathrm{s}$ ( 4 na escala Beaufort) ${ }^{4}$, já no verão é de $\mathrm{E} / \mathrm{SE}$, com força variando entre $3 \mathrm{~m} / \mathrm{s} \mathrm{e} 4 \mathrm{~m} / \mathrm{s}$ (3 na escala Beaufort). Isto significa que, nos meses de inverno, um navio a vela, em plena manobra de entrada na boca da barra do porto do Recife, poderia ser lançado de encontro aos arrecifes ou bancos de areia, no verão, essa possibilidade era pouco comum, mas também passível de mudança brusca do tempo com rajadas que levassem ao soçobro.

Guardando as devidas proporções entre embarcações e navios, os marinheiros mais experientes, em vez de lutar contra o regime dos ventos, os usam a seu favor. Como exemplo, pode-se observar a saída das jangadas no amanhecer, quando o vento está, normalmente, no sentido terra-mar. Já no entardecer, com objetivo de retornar para terra, aproveitam a brisa soprando no sentido inverso.

\section{AS CORRENTES MARINHAS}

O litoral de Pernambuco sofre influência da corrente Sul Equatorial (Benguela) que é quente, com temperatura em torno de $26^{\circ} \mathrm{C}$ e, quando corre paralela à costa nordestina, durante todo o ano, recebe o nome de corrente do Brasil, possuindo uma elevada salinidade (THOMSEN, 1962). Sua velocidade, no período do verão, gira em torno de 1.0 a 2.0 nós/hora, aumentando no inverno.

Além da corrente de Benguela, a área sofre influência de correntes costeiras, formadas pela ação dos ventos que sopram nas proximidades do litoral (monções). Nas proximidades do porto do Recife, ocorrem duas correntes costeiras ao longo do ano: a monção de nordeste e a monção de sudeste. $\mathrm{Na}$ primeira, de setembro a março, a ação dos ventos daquela direção empurra as águas para $\mathrm{SO}$ ou $\mathrm{SSO}$, com velocidades que variam em virtude da força dos ventos. Enquanto que, na segunda, a partir do mês de março, o sentido da corrente se inverte. Ainda, de junho em diante, acontece uma contracorrente, no sentido de S para N (GUEDES, 1975).

Dependendo da intensidade e direção da corrente, o navio pode ser "ajudado" ou "prejudicado" em sua singradura, ou seja, ele pode ganhar ou perder algumas milhas/hora, isto porque ele pode ir de encontro ou a favor da corrente, logo se soma, diminui-se ou, ainda, corrige-se a rota. No caso de uma entrada ou saída de porto, em se tratando de navios a vela, o ideal é trabalhar nas marés de quadratura ${ }^{5}$, pois o aporte de água (as correntes) nesses tipos de marés é mais brando, facilitando a manobra.

\section{A CARTOGRAFIA E SEDIMENTOLOGIA DA ÁREA ADJACENTE AO PORTO DO RECIFE}

A plataforma continental de Pernambuco está inserida na margem continental nordeste - leste do Brasil e tendo, aproximadamente, $180 \mathrm{~km}$ de extensão norte - sul, foi subdividida por Coutinho (1976) em três trechos, levando em consideração os critérios de morfologia e da distribuição dos sedimentos. São eles: plataforma interna, plataforma média, e plataforma externa.

A área portuária do Recife está localizada na plataforma interna, que corresponde à área entre a linha de praia e a isóbata de $-20 \mathrm{~m}$, apresentando, em sua maioria, um relevo suave com poucas irregularidades (canais, bancos 
arenosos e recifes), os quais servem de substrato para o crescimento de corais e algas (CAVALCANTI e KEMPF, 1970).

Nos canais de acesso ao porto, existem recifes submersos e afloramentos rochosos que atuam como perigo isolado, bem como a sua área estuarina recebe sedimentos oriundo dos rios que compõem a bacia do Pina. (RIOS, 2007).

No tocante a sedimentologia, é observada a predominância de areias terrígenas quartzosas de granulometria média a grossa, sugerindo um ambiente de alta energia. (MANSO et al. 2004).

Levando em consideração o relevo portuário descrito, o navegante do século XVI deveria que adentrar e sair do porto do Recife pelos canais de acesso, no ápice das marés de sizígia, isto porque são as que oferecem maior altura da lâmina d'água, distanciando o casco das barreiras físicas do leito marinho.

\section{A NAVEGAÇÃO OCEÂNICA NO SÉCULO XVI}

A navegação oceânica no século XVI era feita em navios de madeira com aparelhos a vela, com uma hidrodinâmica pouco favorável, cuja dependência dos ventos e das correntes era total.

No que concerne à orientação náutica, os instrumentos voltados para navegação eram razoavelmente imprecisos, tais como, a balestilha ${ }^{6}$, o quadrante, o compasso, a agulha ${ }^{7}$ e a carta de marear ${ }^{8}$. A distância e o tempo eram aferidos com a barquinha ${ }^{9} \mathrm{e}$ ampulheta enquanto a profundidade era medida com $\mathrm{o}$ prumo de chumbo atrelado a um cabo graduado com nós.

O descobrimento do Novo Mundo e de uma rota marítima para a Índia e a China, contornando o Cabo da Boa Esperança, foi um grande estímulo para o desenvolvimento da Engenharia Naval em alguns países, tais como Portugal, Espanha, Inglaterra, Holanda e França, que se lançaram aos mares em busca de riquezas. Devido abundância de especiarias no Oriente e no Novo Mundo, a intensificação do comércio corroborou para o aumento do número de navios lançados ao mar, bem como no tamanho das embarcações, que cresceram em comprimento, boca, calado, número de conveses e área vélica (RAMOS, 2000).

O aumento do comércio marítimo fez com que muitos navios soçobrassem por diversos fatores, tais como: patológico (quando o Mestre ou Piloto falecia ou ficava impossibilitado de exercer a sua função por problemas médicos); Humano; Fortuito; Logístico; Bélico; Estrutural (causado pela falta de manutenção ou má construção do navio); Cartográficos e Meteorológicos (RIOS, 2010).

\section{A TIPOLOGIA DAS EMBARCAÇÕES DO SÉCULO XVI}

Como no século em questão, a maioria dos navios soçobrados na área portuária do Recife (nau; galeão e charrua), é oriunda de Portugal, os exemplos serão de navios daquele país. No que concerne às características arquitetônicas, os navios eram construídos com diversos tipos de madeira, normalmente de dentro para fora Skeleton first (BASCH, 1972), ou seja, a quilha e as costelas ${ }^{10}$ sustentavam o costado, a carena ${ }^{11}$, assoalhado ${ }^{12}$, anteparas ${ }^{13}$ e os conveses. 
Eles possuíam formas arredondadas, eram pesados, ronceiros ${ }^{14}$ (com exceção dos caravelões), proa pouco lançada e popa reta, sem muita ventilação interior, com até três conveses e dois castelos.

O aparelho era constituído de dois a três mastros, em sua maioria, com velas redondas e umas poucas latinas, portanto, pouco bolineiros ${ }^{15}$, calando ${ }^{16}$ entre três e seis metros. Já o aparelho de governo tinha leme em madeira com machos $^{17}$ e fêmeas ${ }^{18}$ de bronze, madre ${ }^{19}$ e cana do leme, sistema de fundeio composto de três pares de duas âncoras, cabos e correntes e um cabrestante ${ }^{20}$ manual de quatro pontas.

\title{
O Galeão
}

Os navios que dominaram as rotas das especiarias no século XVI foram os galeõese as naus. Segundo Barreto, 1991, o galeão português do século XVI pode ser considerado a forma terminal da evolução da caravela, embora seja também identificada como uma variante da nau. Tinha até 4 mastros (de vante para ré: traquete, grande, artimão e contra-artimão), envergando velas redondas nos dois primeiros mastros e velas de bastardos nos dois últimos. Deslocava entre 600 a 700 toneladas,a relação entre a boca e o comprimento era de um para quatro, a popa era arredondada e um tanto bojuda e bolinava bem. No que concerne ao armamento e a equipagem, ele estava artilhado com 40 peças de calibres diversos e 100 ou mais tripulantes. (CHERQUES, 1999).

\begin{abstract}
A Nau
Durante a segunda metade do século XV, surge a nau. Era um navio com 3 mastros, sendo dois aparelhos redondos e um latino, com castelos de proa e popa totalmente integrados ao casco. No século XVI, atinge entre $600 \mathrm{e}$ 700 toneladas. Em que pese o fato de ser um navio de comércio, com cerca de 100 tripulantes e 500 passageiros, ela aparece também armada. A nau de guerra comportava entre 60 a 120 peças de artilharia, podendo ser de primeira classe (mais de 100 peças), de segunda classe (90 a 100 peças) ou de terceira classe (60 a 80 peças). Destinava-se a proteger o comércio marítimo e a executar ações bélicas no mar (CHERQUES, 1999).
\end{abstract}

\section{A Charrua}

Existem poucas informações sobre este tipo de navio. Sabe-se que eram destinados ao transporte de víveres, munição e tropas, podendo ter armamento. Tinham 3 mastros e um grande porão (CHERQUES, 1999).

\section{RESULTADOS E DISCUSSÕES}

Um dos maiores perigos dos navios a vela do século XVI, no Nordeste do Brasil, era a entrada e saída da barra dos portos. Essas áreas abrigadas ficavam dentro dos estuários, cuja divisão com o mar é feita, normalmente, por meio dos recifes submersos ou rochas que não afloram na sua totalidade, constituindo-se em perigos isolados, emitindo sinais de suas existências de acordo com as marés. 
Como as atividades de içar ou arriar velas são demoradas e demandam certo número de pessoas, além de harmonia de procedimentos, bem como não existia sonar ou motor de popa, os navios ficavam a mercê dos marinheiros mais experientes para transpor tais obstáculos. Como se tudo isso não bastasse, os ventos podem sofrer mudanças bruscas, ocasionadas por diferenças de pressão atmosférica, acarretando em rajadas repentinas e/ou tempestades (fator hidrometeorológico), que podem quebrar o mastro, rasgar as velas ou romper cabos de fundeio, fazendo com que o navio seja lançado de encontro aos arrecifes (fator cartográfico).

Eram essas as variáveis para quem tentasse adentrar ou sair de um dos portos do nordeste brasileiro, no século XVI, cujo litoral era objeto de estudo cartográfico, aparecendo, de tempos em tempos, cartas com novos detalhamentos e balizas portuárias.

\section{SÍNTESE DOS NAUFRÁGIOS E SEUS FATORES}

Os seis naufrágios que estão nos arrecifes, na sua grande maioria, vieram a soçobrar por desconhecimento da cartografia local (fator cartográfico). $\mathrm{O}$ sinistro do Galeão São João (1551), não está muito claro sugerindo, a princípio, que colidiu e se desfez em um perigo isolado, possivelmente, o local recebeu a toponímia de Baixio do Galeão, tendo sido recuperado parte do material metálico e armamento (PEREIRA DA COSTA, 1983, vol. 1, BERGER et al., 1975).

Outro soçobro, a Nau Santo Antônio, de 200 tonéis, ia zarpar para Portugal, em 16 de maio de 1565, quando, ao atravessar a barra, o vento mudou e, como a maré estava contrária, veio a colidir com os arrecifes, varando-os e aí permanecendo por dois dias, sendo salva após fazer o transbordo da carga e cortar os mastros (PEREIRA DA COSTA, 1983, vol. 1).

A Charrua Boa Ventura (1580) estava fundeada no lamarão externo, quando uma tempestade partiu as amarras de fundeio e a levou de encontro aos arrecifes. (PEREIRA DA COSTA, 1983, vol. 1).

O Galeão São Pedro (1594), que vinha das Índias com um fabuloso tesouro, naufragou ao colidir com os arrecifes do porto, sendo salva toda a sua carga, o que acarretou na vinda de James Lancaster ao Recife para apoderar-se dela. (BERGER et al. 1975 e PICKFORD, 1994).

$\mathrm{Na}$ invasão do istmo de Olinda pelo pirata James Lancaster, uma das cinco lanchas de desembarque (1595) que participaria da tomada de cabeça de praia para assaltar o porto do Recife, bateu em um dos arrecifes submersos, outra foi atingida por um tiro de canhão. (BERGER et al. 1975).

Sinteticamente, podem ser resumidos os naufrágios no porto do Recife e seus respectivos fatores na Tabela 01 abaixo, assim como pode ser observada a distribuição espacial desses naufrágios na imagem 01, a seguir: 
Tabela 01 - Tipologia, nome das embarcações, país de origem, ano e fatores dos naufrágios durante o século XVI na entrada do Porto do Recife

\begin{tabular}{|c|c|c|c|}
\hline $\mathrm{N}^{\circ}$ & TIPO - NOME DO NAVIO - PAÍS & ANO & FATOR DO NAUFRÁGIO \\
\hline 01 & Galeão São João - Portugal & 1551 & Cartográfico \\
\hline 02 & Nau Santo Antônio - Portugal & 1565 & Hidrometeorológico \\
\hline 03 & Charrua Boa Ventura - Portugal & 1580 & Hidrometeorológico \\
\hline 04 & Galeão São Pedro - Portugal & 1594 & Cartográfico \\
\hline 05 & Lancha desembarque - Inglaterra & 1595 & Cartográfico \\
\hline 06 & Lancha desembarque - Inglaterra & 1595 & Bélico \\
\hline
\end{tabular}

Fonte: os autores, 2015.

Imagem 01 - Extrato de carta náutica 902 da DHN com localização dos naufrágios ocorridos no século XIV na entrada do porto do Recife, Pernambuco - Brasil

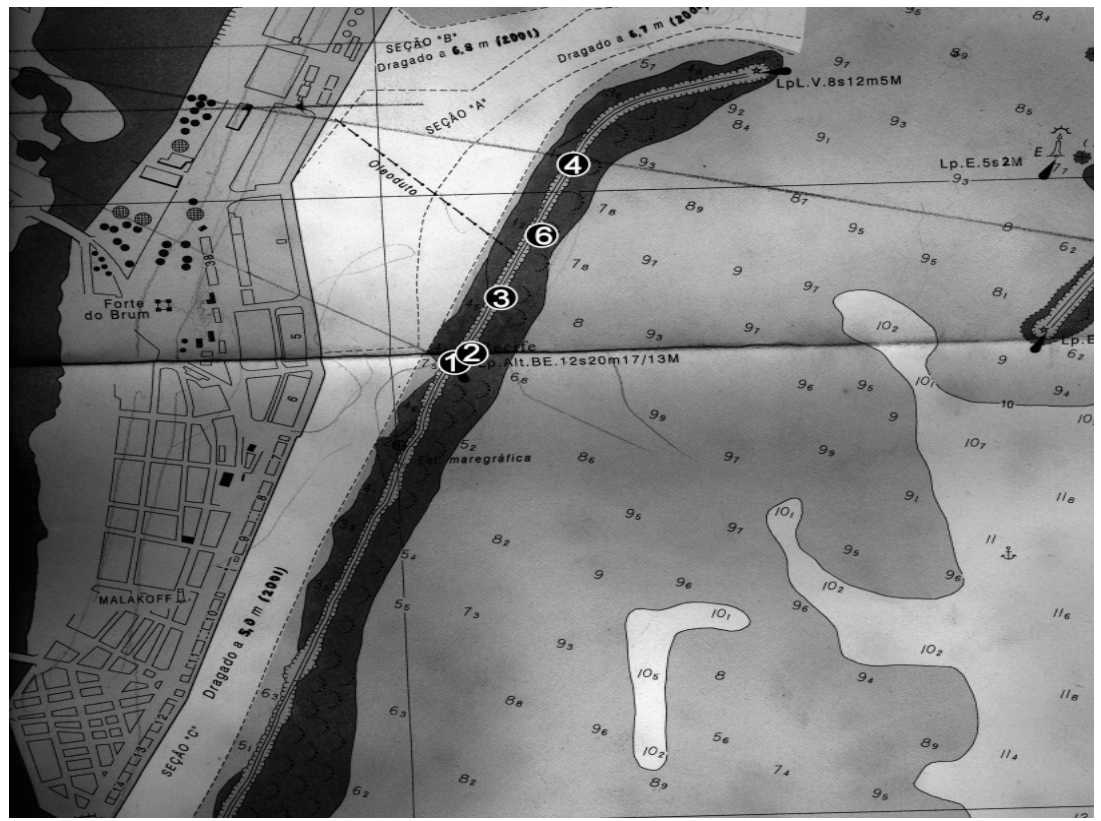

Fonte: Adaptado pelos autores, 2015.

\section{CONCLUSÕES}

Com exceção de um naufrágio de origem bélica, foi possível constatar, pela pesquisa, o desconhecimento de parte dos navegantes da paisagem natural submersa. Corroborando, desta forma, para um incremento dos fatores hidrometeorológicos e cartográficos, no século XVI, nos soçobros dos navios/ embarcações que ocorreram no porto do Recife. Neste contexto, podem ser enumerados os seguintes elementos:

- a) A lâmina d'água escondia a paisagem submarina (relevo) que acarretava em naufrágios, isto porque alguns calados eram incompatíveis com a profundidade local, principalmente nas baixa-mares de sizígia.

- b) As rajadas bruscas de vento - por vezes - partiam as amarras e lançavam os navios contra os cordões de recifes do porto, submersos ou não, acarretando em naufrágio.

- c) É possível afirmar que, mais da metade dos naufrágios ocorridos na entrada do porto do Recife no século XVI, decorreram do desconhecimento parcial da análise espacial da paisagem, mormente do fator cartográfico; 
- d) Em face aos recursos tecnológicos da época, as imprecisões exploratórias preliminares dos dados geomorfológicos (principalmente de subsuperfície) da paisagem do porto resultaram em mapas cartográficos, também, imprecisos que contribuíram para tais naufrágios.

- e) Os registros planimétricos dos navios decorrentes desses naufrágios permitiram elaborar uma análise da paisagem arqueológica do porto do Recife que reforçam, também, o fato dos calados dos navios serem (com exceção da lancha de desembarque) muito próximo do limite das dimensões exigidas pelas duas vias de acesso do porto, ficando a maré como barreira limitante.

O desconhecimento desses fatores hidrometeorológicos e cartográficos resultou na construção, não intencional, de uma paisagem arqueológica com sítios arqueológicos subaquáticos, derivados de naufrágios dessas embarcações.

\section{NOTAS}

${ }^{1}$ Faixa do litoral compreendida entre o mais alto preamar e o mais baixo baixa-mar.

${ }^{2}$ São todos os vestígios da existência humana que tenham um caráter cultural, histórico arqueológico e que tenham estado sob água, parcial ou totalmente, de forma periódica ou contínua, por pelo menos durante 100 anos (art. 1 da Convenção da Unesco).

${ }^{3}$ Carta de previsão de tempo, na qual é registrado um grande número de observações de modo a mostrar a pressão barométrica, temperatura, umidade, direção e força dos ventos, estado do mar, nuvens, na ocasião em que a carta é completada.

${ }^{4}$ Escala criada pelo hidrógrafo inglês Francis Beaufort que faz uma relação entre o tipo de vento e a descrição do mar.

${ }^{5}$ Maré de amplitude mínima que ocorre nos períodos de quarto crescente e de quarto minguante da Lua.

${ }^{6}$ Era também conhecida como raio astronômico, bastão-de-Jacob, vara-de-ouro, radiômetro, balestrilha, báculo-de-Jacob e báculo-de-São Tiago.

${ }^{7}$ Agulha imantada sobre uma rosa dos ventos que se alinha com o campo magnético natural da Terra, permitindo então saber a direção para a qual o navio segue, ou seja, o seu rumo ou derrota.

${ }^{8}$ Confeccionada em couro ou papel, apresentava teias de rumos e escalas gráficas divididas em milhas ou léguas, uma escala de latitudes em graus.

${ }^{9}$ Peça de madeira, atrelada a um cabo graduado em nós, utilizada para medir a velocidade do navio.

${ }^{10}$ Também chamada de baliza ou caverna, peça de madeira perpendicular à quilha, partindo desta para cada bordo, acompanhando o costado e cujo conjunto constitui o arcabouço ou esqueleto estrutural da embarcação, servindo para receber o forro.

${ }^{11}$ Parte do forro exterior do casco que fica abaixo da linha de flutuação.

${ }^{12}$ Pranchões de madeira que cobrem os pavimentos de um navio.

${ }^{13}$ Qualquer painel vertical que secciona internamente uma embarcação ou navio.

${ }^{14}$ Diz-se de navio lento ou vagaroso, o mesmo que cangueiro, zorreiro.

${ }^{15}$ Diz-se navio que navega bem a bolina (contra o vento).

${ }^{16}$ Calado é a distância vertical medida entre a linha de flutuação à face inferior da quilha em qualquer ponto do navio, portanto calando significa quanto do navio está submerso na massa líquida.

${ }^{17}$ Ferragens de forma cilíndrica colocadas espaçadamente por ante a vante da porta do leme e que se encaixam nas fêmeas do cadaste formando as governaduras ou ferragens do leme.

${ }^{18}$ Ferragens vazadas colocadas espaçadamente por ante a vante da porta do leme e que recebe o macho do cadaste formando as governaduras ou ferragens do leme.

${ }^{19}$ Eixo do leme que atravessa o casco e através do qual se movimenta o leme. 
${ }^{20}$ Aparelho de força constituído de uma saia vertical montada em torno de um eixo para operar uma amarra de corrente, nesse caso acionado manualmente com barras enfiadas em casas praticadas no chapéu.

\section{REFERÊNCIAS}

ALBERNAZ I, João Teixeira. Livro que Dá Razão do Estado do Brasil. Rio de Janeiro: Ministério da Educação e Cultura, 1968.

BARRETO, Luís Felipi. Os navios do descobrimento. Lisboa: Correios de Portugal, 1991.

BASCH, Lucien. Ancient wrecks and the archaeology of ships. The International Journal of Nautical Archaeology, n.1, 1972.

BERGER, Paulo; WINZ, Antônio Pimentel; GUEDES, Max Justo. Incursões de corsários e piratas à costa do Brasil: 1500 - 1600. In: História Naval Brasileira. Rio de Janeiro: Serviço de Documentação da Marinha, v. 1, tomo II, 1975.

BOADO, Felipe Criado. Del terreno al espacio: plantamientos y perspectivas para la arqueologia del paisage. Capa-criterios y convenciones em arqueologia del paisage. Santiago de Compostela: Universidade de Santiago de Compostela, n. 6, 1999.

BERNER, Elizabeth Kay.; BERNER, Robert A. Global environment: water, air, and geochemical cycles. New Jersey: Prentice-Hall, 1996.

CAVALCANTI, Lourinaldo Barros; KEMPF, Marc. Estudos da plataforma continental na área do Recife (Brasil) - II. Meteorologia e hidrologia. Recife: UFPE, 1970.

CHERQUES, Sérgio. Dicionário do mar. São Paulo: Globo, 1999.

COUTINHO, Paulo Nóbrega. Geologia marinha da plataforma continental Alagoas-Sergipe.Tese (Livre Docência) - UFPE, Recife, 1976.

FERRO, Maria Isabel Trindade. Percursos e patrimônio na percepção da paisagem. Relatório de final de curso. Universidade Técnica de Lisboa, Instituto Superior de Agronomia, Lisboa, 2004.

FORD, Roger; GIBBONS, Tony; HEWSON, Rob; JACKSON, Robert; ROSS, David.The encyclopedia of ships. London: Amber Books, 2001.

GUEDES, Max Justo. História Marítima do Brasil. Rio de Janeiro: Ministério da Marinha, Serviço de Documentação, 1975.

GUERRA, Flávio. Arrecife de Sam Miguel. Recife:Arquivo Público Estadual, 1954.

LINS JUNIOR, Hamilton Marcelo Morais. Arqueologia Marítima: a evolução da canoa monóxila em Pernambuco, Brasil (séc. XVI - XX). Dissertação (Mestrado em Arqueologia). Recife: UFPE, 2015.

LUCENA, Leandro Ricardo Rodrigues; SILVA, Danila Maria Almeida Abreu; STOSIC, Tatijana. Lacunaridade da Direção do Vento em Estações Meteorológicas de Pernambuco. Recife: UFRPE, 2012.

MACKENZIE, Frederick Theodore Our changing planet. New Jersey: Prentice-Hall, 1998.

MANSO, Valdir Amaral Vaz; VALENÇA, Lúcia Maria Mafra; COUTINHO, Paulo Nóbrega; GUERRA, Núbia Chaves. Oceanografia: um cenário tropical. Org. Enide Eskinase-Leça; Sigrid Neumann-Leitão; Monica Ferreira da Costa. Recife: Bagaço, 2004.

MARINHA DO BRASIL. Carta Náutica $N^{\circ}$ 902. Rio de Janeiro: Diretoria de Hidrografia e Navegação, 1997. 
MELLO, José Antônio Gonsalves; ALBUQUERQUE, Cleonir Xavier. Cartas de Duarte Coelho a El Rei. Recife: Massangana, 1997.

PEREIRA DA COSTA, Francisco Antônio. Anais Pernambucanos. 2. ed. Recife: Fundarpe, 1983.

RAMOS, Flávio Pestana. Naufrágios e obstáculos enfrentados pelas armadas da Índia Portuguesa: 1497 - 1653. São Paulo: Humanitas /FFLCH / USP, 2000.

RIOS, Carlos. Identificação arqueológica de um naufrágio localizado no lamarão externo do porto do Recife, PE, Brasil. Dissertação (Mestrado em Arqueologia). Recife: UFPE, 2007.

.; VALLS, Marcela. Carta Arqueológica de naufrágios do litoral de Pernambuco: de 1503 a 1600. Clio, n. 24, 2008.

. Subsídios para a Arqueologia Subaquática: Fatores Causadores de Naufrágios. Navigator, v. 06, n. 11, 2010.

.; GHETTI, Neuvânia; SILVA, Carolina; LIMA, Izabela; ROCHA, Lucas. Cruz do Patrão: está no lugar certo ou não? Recife: Edufepe História Ambiental debates interdisciplinares, 2013.

PICKFORD, Niger. O atlas dos naufrágios e tesouros. Londres: Dorling Kindersley, 1994.

TEIXEIRA, Luiz. Roteiro de todos os sinais na costa do Brasil. Rio de Janeiro: Ministério da Educação e Cultura, 1961.

TILLEY, Christopher. Phenomenology of landscape: places, paths and monuments. Oxford: Berg Burg Pub. Ltda, 1994.

THOMSEN, Hamilton. Essentials of Oceanography. New Jersey: Prentice Hall, 1962.

UNESCO. La convención de la Unesco sobre la protección del Patrimonio Cultural Subacuático. Paris, 2001. 
